\title{
Good Clinical Practice (GCP) - an alternative, unarticulated narrative
}

\author{
SAMIR MALHOTRA
}

\begin{abstract}
GCP has become the gold-standard for clinical research; initiated as a guideline pertaining to new drug development, it became a law in many countries, extending its scope to include all research. GCP is an excellent document that outlines the responsibilities of stakeholders involved in clinical research. Widely acclaimed, and deservedly so, it is considered as the "goto" document whenever questions arise during the conduct of a clinical trial. This article presents another narrative, one that has not been articulated so far. Irrespective of whether we consider GCP as a law or a guideline, it is viewed as an "official" document, without the overt realisation that this was actually an initiative of the pharmaceutical industry, the "masters of mankind". While the stress on documentation and monitoring in GCP was justified, its over-interpretation led to increased costs of clinical trials, with the result that smaller companies find it difficult to conduct the already expensive trials. GCP as an idea is now so entrenched within the scientific community that the real aims which led to its birth and that can be mined from the ICH website, like the need for market expansion, have remained largely unnoticed and undocumented, and are being expressed here.
\end{abstract}

Keywords: ICH, GCP, alternative narrative, market, pharmaceutical industry

We rarely hear of combinations of masters, though frequently of workmen. Masters are always and everywhere in a sort of tacit, but constant and uniform, combination. Adam Smith - Wealth of Nations,

"GCP is an ethical and scientific quality standard for clinical research," proclaimed the senior scientist from the USA,

Author: Samir Malhotra (Malhotra.samir@pgimer.edu.in), Professor and Head, Department of Pharmacology, Postgraduate Institute of Medical Education and Research (PGIMER), Chandigarh, 160012 INDIA.

To cite: Malhotra S. Good Clinical Practice (GCP) - an alternative, unarticulated narrative. Indian J Med Ethics. Published online on August 25, 2021.DOI: 10.20529/IJME.2021.064

Peer Reviewer:Two anonymous peer reviewers

c Indian Journal of Medical Ethics 2021 earnestly and enthusiastically, in the lavish hall of a 5-star Mumbai hotel, as we, the participants of a workshop organised by the United States (US) National Institutes of Health (US NIH) and the Food and Drug Administration (FDA) in collaboration with an Indian counterpart, keenly attempted to absorb the wisdom of the high-profile US team. "It will soon bring India to the topmost echelons of research in the world," he added confidently. This was nearly two decades ago.

I first heard about the Good Clinical Practice (GCP) standard when undergoing DM Clinical Pharmacology training at the Post Graduate Institute (PGI), Chandigarh in the late 1990s, during an annual workshop. The speaker, a charming, witty speaker from a leading pharmaceutical company, extolled the virtues of GCP as if it was the most important milestone in the history of clinical research. At the time few knew about GCP outside the leading institutes.

A few years later, GCP had established itself as a term so important that lack of familiarity with which could fail a medical examinee, at least in specialties with a high proportion of clinical research. This was thanks to the thousands of workshops, seminars and lectures, more or less high-profile, yet not lacking in quality, spirit and devotion, often conducted by those who had earlier attended the initial sessions.

This idea crystallised in 1996, capturing the global imagination like few others had in the past, so that, starting as a guideline, it went on to become the law in many countries, including ours. Its formal definition as, " an international ethical and scientific quality standard for designing, conducting, recording and reporting trials that involve the participation of human subjects," (1). was elaborated further: "Compliance with this standard provides public assurance that the rights, safety and well-being of trial subjects are protected, ... and that the clinical trial data are credible." These two sentences appear to set the tone - it is about patients and data - both indubitably being the highest objectives of clinical research. This is what we were taught and in turn taught our residents.

The year of conception of GCP must be considered to be 1990, when the European Federation of Pharmaceutical Industries and Associations (founded in 1978) hosted a meeting in Brussels, attended by European, Japanese and US regulatory agencies and industry associations and founded the 
International Conference on Harmonisation (ICH); though the process had begun in the 1980s in Europe as it "moved towards the development of a single market for pharmaceuticals" (2). What was to be harmonised? Why was this required?

First of all, GCP was an initiative of the Pharma industry. The goal was to harmonise regulatory requirements for new drugs to ensure the uniformity of approval processes in Europe, USA and Japan (3) the largest markets. Nevertheless, from the 1980s to 1996, the successes achieved were relatively minor, if compared with the behemoth it is today. The real accomplishment was establishing a partnership with the World Health Organization (WHO), at its 1989 Conference of Drug Regulatory Authorities - "Soon afterwards, the authorities approached International Federation of Pharmaceutical Manufacturers and Associations to discuss a joint regulatory-industry initiative on international harmonisation, and ICH was conceived" (2) in 1990.

The thalidomide tragedy - the birth of thousands of babies with phocomelia in the middle of the last century - led regulatory authorities all over the world to re-evaluate their laws regarding testing, approval and marketing of medicines (4). Additionally, the Declaration of Helsinki (1964) (5), an influential paper (1966) on ethics (6), the Tuskegee syphilis study (1932-1972) (7), preceded by the Nuremberg Code (1947) (8), had brought research ethics into focus with the result that, "For most countries, whether or not they had initiated product registration controls earlier, the 1960s and 1970s saw a rapid increase in laws, regulations and guidelines for reporting and evaluating the data on safety, quality and efficacy of new medicinal products," states the ICH website (2).

Put simply, the increasingly stringent laws and differing requirements for approvals in different countries were making new drug approvals harder, delayed, with enormous implications for profit and globalisation. And this was a challenge, as, "The industry, at the time, was becoming more international and seeking new global markets"(2). But since it would be awkward to propose market globalisation as a rational argument, it had to be conveniently concealed under superior, even altruistic explication - "The urgent need to rationalise and harmonise regulation was impelled by concerns over rising costs of health care, escalation of the cost of R\&D and the need to meet the public expectation that there should be a minimum of delay in making safe and efficacious new treatments available to patients in need" (2). It requires no guesswork to know which explanations we were getting in those workshops, which by the way, were often conducted in partnership with multinational pharma companies.

The entry into India was not accidental, "As ICH started into a new millennium, the need to expand communication and dissemination of information on ICH Guidelines with non- $\mathrm{ICH}$ regions became a key focus" (2). Whenever developed countries' multinationals enter markets of developing nations, they seek three elements: markets for their products, natural resources, and cheap labour. India was exceptionally suitable on all three counts - abundant, often drug-naive patients with diverse illnesses, serving as natural resources; well-trained, English-speaking physicians as willing partners available at a low price; and a large market for their new drugs.

As the $\mathrm{ICH}$ grew and conquered newer territories, it kept on providing several guidance documents, on quality $(\mathrm{Q})$, safety $(\mathrm{S})$, efficacy $(\mathrm{E})$, and multidisciplinary $(\mathrm{M})$ - QSEM; GCP E6 is the most important and widely-known guideline. There is no doubt that these guidelines are valuable as they provide useful information to the companies regarding standardisation of product quality procedures, evaluation of safety and efficacy, and harmonisation of regulatory review procedures, documents and medical terms.

In the meanwhile, registering as a non-profit legal entity under Swiss Law in 2015, ICH evolved into the International Council on Harmonisation - note this transition - from Conference to Council - showing maturation, authority, policy-making, decision-taking aspects of a Council versus a Conference. GCP, starting as a guideline for trials on new drugs requiring regulatory approval only, was included in regulations of many countries, encompassing all clinical studies.

We would be misguided to imagine that the ICH/GCP sought relaxation of regulations - that wasn't the case. While the leading Pharma companies asked for uniformisation of regulations, the intention was to make regulations more rigorous. For instance, just one sentence that trials should be monitored, had immense consequences - trial monitoring became big business, small companies that had been involved in some clinical-research-related business pre-GCP, became multi-billion-dollar Contract Research Organisations, consolidating, centralising, growing (11.4\%), expanding projected to reach US\$>90 billion by 2026 (9), leading to cost escalations. The excessive stress on documentation $(>50$ essential documents for a trial) also meant more staff was required to handle GCP-compliant trials, increasing costs, making new drug development even less affordable for smaller companies.

As clinical research became more expensive, smaller companies, especially Indian companies, which had developed strong capabilities for new drug development, found themselves unable to compete. This happens with other industries as well - larger companies pursue stricter regulations to edge out smaller competitors. Worldwide, although a significant proportion of small companies managed to file New Drug Applications, their molecules were outsourced - greater numbers of drugs currently being acquired than developed in-house (10).

Some shortcomings of GCP were acknowledged in a 2016 addendum ICH GCP has been "misinterpreted \& implemented in ways that impede innovation by, for example, emphasizing 
less important aspects of trials ........... at the expense of critical aspects......" (11) and this called for improvement in business efficiency of industry (12), as outlined in the third revision, in which "a full rewrite and reorganization" is being proposed, which "would likely primarily benefit innovators who typically conduct clinical trials, such as those in the pharmaceutical and biotech sectors" (Final Business Plan document) (13) confirming the perception that it was always more about business than patients/data such transparency, although desirable, reflects more on the confidence accrued over two decades rather than a desire for openness. In any case, the definition of GCP itself does give a hint when it states that it is about public perception (1).

The GCP then goes on to delineate the responsibilities of the institutional ethics committees (ECs), Principal Investigators (PI) and sponsors, aspects that enable it to be called an ethical and scientific document. The IEC responsibilities are comprehensible, logical and elaborate although hardly original. Nevertheless, a phrase does convey the underlying message the IEC must "review a proposed clinical trial within a reasonable time" - that speed is the sine qua non of capital, being directly linked to revenues, embodied in the lives of patents.

After the events of the 1960s-70s mentioned earlier, ECs were constituted in most institutions and, in their zeal to prevent unethical research, might have caused delays in project approvals, at the time when the leading pharma companies were looking for new markets in their plans to globalise. In any case, ECs were perceived as obstacles to research, and years later, GCP would tell ECs to review projects swiftly (1). The gap in-between was admirably filled by one of the most wellknown documents in bioethics - the Belmont Report (14). Turning ethics into 'Principlism', with its deterministic focus on principles, obscuring the ethical review process, converting it into 'checklist ethics' (15), the Report, perhaps unintentionally, played into the hands of those who claimed ECs are obstacles to research, leading the pharma associations - the combination of masters (Adam Smith) - to tell the ECs to speed up. Principlism became the main ethical theory around the decades when everything was becoming business, including research, converting ethics into a one-point event, captured in, and culminating in that mini-miracle, that is, the EC approval letter. Private, for-profit, independent ECs (16) sprang up with advertisements claiming guaranteed, swift approvals.

Another parallel event that was crucial to the GCP-isation of research is linked with monopoly practices, smartly, conveniently disguised as intellectual property. Thanks to the Indian Patents Act (1970) (17), the clause of allowing 'process patent' but not 'product patent', permitted Indian companies to become world leaders in generic drugs. Recognising this as a big threat, the multinationals intensified their successful campaign for abolishing the process patent system through the General Agreement on Tariffs and Trade and the Agreement on Trade-Related Aspects of Intellectual Property
Rights (GATT-TRIPS), later the World Trade Organization (WTO) (1995-2005). The prices of medicines increased (18), along with them the profits, at the same time GCP regulations ensured that new drug development became so expensive that smaller companies were unable to market new drugs.

That is why, in my view, GCP is a crucial component of the globalising, market-capturing plan of the major companies, who invented the idea, and then tricked the governments, regulators and even the $\mathrm{WHO}$ into not only adopting it, but also to universalising it, demonstrating that "For any way of thought to become dominant, a conceptual apparatus has to be advanced that appeals to our intuitions and instincts, to our values and our desires, as well as to the possibilities inherent in the social world we inhabit. If successful, this conceptual apparatus becomes so embedded in common sense as to be taken for granted and not open to question" (19) The ingenious use of governments, WHO, with scientists quickly toeing the line, and the WTO support made this job quite effortless for the industry leaders. Otherwise, can you imagine a Pharma representative telling you how to do ethical and scientific research?

As everyone was singing the GCP song (we also jumped on the bandwagon, publishing articles $(20,21,22)$ and books $(23,24)$ about GCP), no one even questioned whether there can be an adverse impact on clinical research worldwide and India/other developing nations specifically. Thinking of GCP as a golden gift to clinical research, we imagined global clinical research would soon become perfect, with India as the world leader - after all, the governments and our own scientists were telling us so repeatedly in different workshops and on various platforms. Is post-GCP research, in fact, of higher quality? Are the ethical and scientific standards much higher? Are the data more credible? Has research misconduct declined? Are patients being protected better?

It would be worthwhile to conduct a systematic review to compare these aspects pre- and post- GCP. There are no data to suggest that there has been an increase in quality; on the contrary, it has been suggested that increasing complexity in clinical trials ( $>200 \%$ rise in the number of CRF pages from 1999 to 2005) could have an adverse impact (25). There are also no data to indicate that research misconduct declined post-GCP; in fact, anecdotal reports suggest it may be increasing or at least not declining $(26,27,28,29)$. The case of Robert Fiddes alone is sufficient to elucidate this (30), as sponsors' repeated monitoring visits and FDA inspections failed to detect any GCP-related issues. Dr Fiddes managed research fraud of gigantic proportions, spread hundreds of studies, generating fictitious data, spurious samples, and enrolling non-existing patients in trials.

The one-sidedness of this article is deliberate - GCP has garnered a lot of admiration, justifiably, but much has been written about that. Instead, I have consciously focused on an alternative, hitherto unexplored narrative, one that 
emphasises the complex, yet inter-related underpinnings of this process with apparently unconnected but simultaneous motives and events. By mining the $\mathrm{ICH}$ website to elucidate this narrative, I have shown that the underlying agenda provided by the associations of the biggest pharma companies was not simply about patients and data, but a bigger plan involving elements of the modern market society we currently live in.

Increasing marketisation of everything has not provided the expected results, "The current market for healthcare just doesn't deliver. It is deeply, perhaps fatally, flawed. Even market economists themselves don't believe in it anymore. It's now so dysfunctional that I sometimes think the only solution is to blow the whole thing up" (31) writes Rosenthal about the US system. And we know that developed countries are mirrors of the future for developing countries. In future, let us beware of any "novel" ideas that come disguised as scientific or ethical, reforms but in reality, involve questionable aims.

Acknowledgements: Discussions with colleagues, residents and students over journal clubs, seminars and coffee clubs

\section{References}

1. Integrated addendum to ICH E6(R1): Guideline for Good Clinical Practice E6(R2).ICH;2016 Nov 9[cited 2021 Jun 15]. Available from: https://database.ich.org/sites/default/files/E6_R2_Addendum.pdf.

2. International Council for Harmonisation. History. $\mathrm{ICH}$; date unknown [cited 2021 Jun 7]. Available from: https://www.ich.org/page/history.

3. International Council for Harmonisation. Mission. Harmonization for Better Health. ICH; date unknown [cited 2021 Jun 13]. Available from: https://www.ich.org/page/mission.

4. Science Museum. Thalidomide. 2019 Dec 11[cited 2021 Jun 14]. Available from https://www.sciencemuseum.org.uk/objects-andstories/medicine/thalidomide

5. World Medical Association. Declaration of Helsinki. Adopted by the 18th World Medical Assembly, Helsinki, Finland. 1964 Jun [cited 2021 Jun 14]. Available from; https://www.wma.net/wp-content/uploads/ 2018/07/DoH-Jun1964.pdf..

6. Beecher HK. Ethics and Clinical Research. N Engl J Med. 1966 Jun 16[cited 2021 Aug 19]; 274(24):1354-60. Available from: https:// www.nejm.org/doi/10.1056/NEJM196606162742405? url_ver=Z39.88-

2003\&rfr_id=ori\%3Arid\%3Acrossref.org\&rfr_dat=cr_pub+ +0pubmed

7. US Centers for Disease Control and Prevention. The U.S. Public Health Service Syphilis Study at Tuskegee. Updated 2021 Apr 22[cited 2021 Jun 14]. Available from: https://www.cdc.gov/tuskegee/ timeline.htm.

8. The Nuremberg Code (1947). BMJ. 1996[cited 2021 Jun 14]; 313:1448. Available from: doi:10.1136/bmj.313.7070.1448

9. Contract Manufacturing Organization (CMO) Market Size, Share and Industry Analysis. By Type, (API Manufacturing, Finished Dosage Form Manufacturing, (Solid Dosage Form, Injectables and Others), and Packaging), and Regional Forecast, 2019 to 2026. Fortune Business Insights; date unknown [cited 2021 Aug 19]. Available from: https://www.fortunebusinessinsights.com/contract-manufacturing- organization-cmo-market-102658

10. Drug approval trends: Significant acceleration in recent years. 2020 July 1 [cited Jun 13, 2021]. Available from: https:// www.pharmasalmanac.com/articles/drug-approval-trendssignificant-acceleration-in-recent-years.

11. Final Concept Paper Addendum for ICH E6: Guideline for Good Clinical Practice. 2014 June 5 [cited Jun 13, 2021]. Available from: https://database.ich.org/sites/default/files/

E6_R2_Concept_Paper_0.pdf.

12. Final Business Plan Addendum for ICH E6: Guideline for Good Clinical Practice. 2014 June 4 [cited Jun 13, 2021]. Available from: https:// database.ich.org/sites/default/files/E6_R2_Business_Plan_0.pdf.

13. Final Business Plan ICH E6(R3): Guideline for Good Clinical Practice. 2019 November 17 [cited June 13, 2021]. Available from: https:// database.ich.org/sites/default/files/E6R3 FinalBusinessPlan 2019 1117.pdf

14. The Belmont Report. 1979 April 1817 [cited June 14, 2021]. Available from: https://www.hhs.gov/ohrp/regulations-and-policy/belmontreport/read-the-belmont-report/index.html.

15. Clouser KD, Gert B. A critique of principlism. J Med Philosophy. 1990; 15:219-36.

16. Nagarajan R. Experiments with untruth. Times of India. 2011 July 11 [cited Jun 17, 2021]. Available from: https:// timesofindia.indiatimes.com/home/sunday-times/deep-focus/ experiments-with-untruth/articleshow/9167894.cms.

17. The Patents Act, 1970. Delhi: Union Ministry of Law and Justice; 1978 [cited June 17, 2021]. Available from: https://ipindia.gov.in/ writereaddata/Portal/IPOAct/1_31_1_patent-act-197011 march2015.pdf.

18. Bhagat R, Shafiq N, Malhotra S. Analysis of Time Trend of Cost of Medications. J Postgrad Med Edu Res 2020;54:34-6.

19. Harvey D. A brief history of neoliberalism. Oxford: Oxford University Press. 2005. 256 pgs.

20. Shafiq N, Pandhi $P$, Malhotra S. Investigator-initiated pragmatic trials in developing countries--much needed but much ignored. $\mathrm{Br} J \mathrm{Clin}$ Pharmacol. 2009;67:141-142.

21. Shafiq N, Kumari S, Kumar V, Suri V, Muralidharan J, Duseja A, Bansal A, Malhotra S. On-site monitoring of clinical trials by an Ethics Committee in India: a road less travelled. Research Ethics. 2021; 17: 4554.

22. Shafiq N, Malhotra S. Ethics in clinical research: need for assessing comprehension of informed consent form? Contemp Clin Trials. 2011;32:169-72.

23. Malhotra S. Shafiq N, Pandhi P. A Comprehensive Clinical Research Manual. Delhi: Jaypee Brothers Medical Publishers Pvt. Limited. 2009.

24. Malhotra S, Shafiq N, Pandhi P. All that you wanted to know about Clinical Research. Delhi: Ind-Swift Communications (P) Ltd/Star Educational Books Distributor Pvt. Ltd, 2006.

25. Getz K. Protocol design trends and their effect on clinical trial performance. RAJ Pharma. 2008:5:315-6.

26. Kornfeld DS. Perspective: research misconduct: the search for a remedy. Acad Med. 2012;87:877-82

27. Hoogendoorn $M L$, de Lange A. Scientific misconduct in the pharmaceutical industry. Social Cosmos. 2013;4:34-9.

28. Fanelli D. How Many Scientists Fabricate and Falsify Research? A Systematic Review and Meta-Analysis of Survey Data. PLoS ONE. 2009; 4(5): e5738. https://doi.org/10.1371/journal.pone.0005738.

29. Wajman JR, Marin SMC, Bertolucci PHF, Chaves MLF, Bromley T. Qualitative features in clinical trials: coordinates for prevention of passive and active misconduct. Int J Clin Trials. 2018;5:5-11.

30. Swaminathan V, Avery MA. FDA Enforcement of Criminal Liability for Clinical Investigator Fraud. Hastings Sci. \& Tech. L.J. 2012[cited 2021 Jun 16]; 4(2):325. Available from: https://repository.uchastings.edu/ hastings_science_technology_law_journal/vol4/iss $2 / 2$.

31. Rosenthal E. An American sickness: how healthcare became big business and how you can take it back. Penguin Press. USA. 2018.656 pgs. 